\title{
Characterization of sponge-associated actinobacteria with potential to promote plant growth on tidal swamps
}

\author{
Dwi Retnowati, ${ }^{1}$ Dedy Duryadi Solihin, ${ }^{1}$ Munif Ghulamahdi, ${ }^{2}$ Yulin Lestari ${ }^{1,3}$ \\ ${ }^{1}$ Department of Biology, Faculty of Mathematics and Natural Sciences, Bogor Agricultural University, Bogor; \\ ${ }^{2}$ Department of Agronomy and Horticulture, Faculty of Agriculture, Bogor Agricultural University, Bogor; ${ }^{3}$ Tropical \\ Biopharmaca Research Center, Bogor Agricultural University, Bogor, Indonesia
}

\begin{abstract}
Tidal swamps have become one of the highlighted topics in agricultural land development. Rice productivity in a tidal swamp is still low due to the high concentration of $\mathrm{Fe}, \mathrm{Al}$, and low $\mathrm{pH}$. Siderophore-producing bacteria were known to alleviate the toxicity of heavy metals for plants. However, the potential of
\end{abstract}

Correspondence: Yulin Lestari, Department of Biology, Faculty of Mathematics and Natural Sciences, Bogor Agricultural University, P.O. Box 220, Bogor 16002, Indonesia.

Tel. +62.2518622833 - Fax: +62.2518622833 .

E-mail: yulinlestari@gmail.com

Key words: Plant growth promoter; Sponge-associated actinobacteria; Tidal swamps characters.

Contributions: DR contributed to the experimental works, data analysis, and paper writing; DDS contributed to the interpretation of data and paper writing; MG contributed to the interpretation and data analysis; YL led the project, designed the research activities and was involved in paper writing.

Funding: funding from Bogor Agricultural University, Indonesia.

Conference presentation: part of this paper was orally presented at the International Kasetsart University Science and Technology Annual Research Symposium (I-Kustart), Bangkok, Thailand, May 30-June 1, 2018.

Acknowledgments: this study was supported by Ministry of Research, Technology, and Higher Education Republic of Indonesia, through a Master Program of Education leading to Doctoral Degree for Excellence Graduate (PMDSU) scholarships.

Received for publication: 28 March 2019.

Revision received: 7 July 2019

Accepted for publication: 24 July 2019.

${ }^{\circ}$ Copyright: the Author(s), 2019

Licensee PAGEPress, Italy

Journal of Biological Research 2019; 92:8191

doi:10.4081/jbr.2019.8191

This article is distributed under the terms of the Creative Commons Attribution Noncommercial License (by-nc 4.0) which permits any noncommercial use, distribution, and reproduction in any medium, provided the original author(s) and source are credited. sponge-associated actinobacteria has been rarely reported in siderophore production. This work aimed to characterize the sponge-associated actinobacteria based on their tidal swamps characters and their potency to produce plant growth promoter on stressful tidal swamp imposed characters. The in vitro assay showed that, at the presence of $\mathrm{Fe}$ and $\mathrm{Al}$, Car21t isolate produced a dry weight of mycelium reaching up to $289 \mathrm{mg}$ and 204 $\mathrm{mg}$ in Yeast Malt Extract medium, respectively. Interestingly, all isolates were able to grow in relatively high salinity condition (7\%). Indeed, under stress condition, inoculum of five actinobacteria isolates could produce Indole Acetic Acid and siderophore. These experimental results suggested that all potential isolates provided beneficial effects on the host plant, as evidenced by the rise of root length $(9.86 \%)$, shoot length $(9.44 \%)$, and root number $(13.93 \%)$. Subsequently, our experimental data also indicated that these potential isolates belonged to the genus Streptomyces.

\section{Introduction}

Rice plant is the main food crop in Indonesia, being a staple food for more than half of the population in this country. Furthermore, rice consumption continuously increases due to population growth; on the other hand, loss of agricultural land due to the land conversion is also rising. Interestingly, the tidal swamp can be a potential alternative to farming land, but it is hindered by the presence of heavy metals (particularly Al and $\mathrm{Fe}$ ) and deleterious chemical conditions (low $\mathrm{pH}$ and high salinity).

Siderophores are small, high-affinity Fe-chelating compounds which can be produced by bacteria. Binding of the siderophore to a metal can alters the free metal concentration. Soon thereafter, the siderophore-metal complex could be assimilated by the bacteria. Nonetheless, on a way to alleviate the toxicity of heavy metals in plant, it may involve the use of siderophore-producing bacteria. ${ }^{1}$

Previous research suggests that sponge-associated actinobacteria have the ability to produce siderophore (data not shown). Forty-five isolates of sponge-associated actinobacteria can produce siderophore ranging from $2 \%$ to $82.11 \%$. Ten potential isolates of sponge-associated actinobacteria were selected and characterized as plant growth promotion bacteria based on tidal swamp characters. The aim of this research was to assess the capability of sponge-associated actinobacteria in producing the plant growth promotion activity under normal and stress condition based on tidal swamp characters. 


\section{Materials and Methods}

\section{Actinobacteria isolates}

Ten isolates of sponge-associated actinobacteria used in this study were isolated from five different sponges, i.e. Callyspongia sp., Callyspongia aerizusa, Carteriospongia contorta, Chelanoplysilla sp., and Diacarnus bismarckensis from Taman Nasional Kepulauan Seribu, Indonesia. All isolates were grown on Inorganic Salt Starch Agar (ISP4) medium and incubated for 7 days at room temperature.

\section{Stress condition assay for the growth of sponge-associated actinobacteria}

Sponge-associated actinobacteria isolates were characterized based on growth capability on several $\mathrm{pH}$ levels, $\mathrm{NaCl}, \mathrm{Fe}$, and $\mathrm{Al}$ concentration. Isolates were grown on Yeast Malt Extract (ISP2)

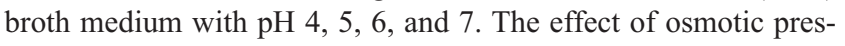
sure on the growth of actinobacteria isolates was observed by adding various levels of $\mathrm{NaCl}(1,3,5$, and 7\%). ISP2 medium supplemented with gradual series of Fe $(0,200,400,600$, and 800 $\mathrm{mg} / \mathrm{L})$ and $\mathrm{Al}(0,250,500,750$, and $1000 \mathrm{mg} / \mathrm{L})$ incubated for 10 days in a shaking incubator at $120 \mathrm{rpm}$. Each test was made at three replicates. Following incubation period, actinobacteria mycelium was filtered using Whatman paper No. 1, for measurement of mycelium dry weight.

Five isolates with the best growth on stress condition were selected. These isolates were grown on ISP2 medium with $\mathrm{pH} 3$, $\mathrm{NaCl}$ 3\%, Fe $600 \mathrm{mg} / \mathrm{L}$, and $\mathrm{Al} 750 \mathrm{mg} / \mathrm{L}$ considered as tidal swamps characters with three replications. The mycelium dry weight was measured as above.

\section{Siderophore production assay on stress condition}

The production of siderophore was evaluated by estimation of siderophore units prescribed by Schwyn and Neilands; ${ }^{2}$ spongeassociated actinobacteria isolates were inoculated on Succinate iron-free medium amended with $3 \% \mathrm{NaCl}, 600 \mathrm{mg} / \mathrm{L} \mathrm{Fe}, 750 \mathrm{mg} / \mathrm{L}$ $\mathrm{Al}$, and $\mathrm{pH} 3$, followed by incubation for 10 days at room temperature on a rotary shaker. This part was made at triplicate for each test. Cells were then collected by centrifugation at $10.000 \mathrm{~g}$ for 20 minutes. Finally, $0.5 \mathrm{~mL}$ blue dye reagent was added to the supernatant. The absorbance was measured at $630 \mathrm{~nm}$ using UV-Vis Spectrophotometer. Color change was observed and measured colorimetrically and then a percentage of siderophore units was measured by using particular equation as follows: (\%) siderophore units $=[(\mathrm{Ar}-\mathrm{As}) / \mathrm{Ar}] \times 100$, where $\mathrm{Ar}$ is absorbance of blank and As is absorbance of sample.

\section{Colorimetric assay for Indole Acetic Acid determination on stress condition}

Indole Acetic Acid (IAA) content was determined according to the method of Patten and Glick ${ }^{3}$ with some modifications. An agar plug ( $9 \mathrm{~mm}$ in diameter) of 10 days old actinobacteria culture was transferred into $30 \mathrm{~mL}$ ISP2 broth medium containing $200 \mathrm{mg} / \mathrm{L} \mathrm{L}-$ tryptophan amended with $3 \% \mathrm{NaCl}, 600 \mathrm{mg} / \mathrm{L} \mathrm{Fe}, 750 \mathrm{mg} / \mathrm{L} \mathrm{Al}$, and $\mathrm{pH} 3$. Each test in this stage was carried out at triplicate. The inoculated media were incubated at $25{ }^{\circ} \mathrm{C}$ for 7 days. A total of 0.5 $\mathrm{mL}$ cell-free supernatant was mixed with $1 \mathrm{~mL}$ Salkowski's reagent and kept at the darkroom for 30 min until pink color developed. Optical density was measured using spectrophotometer at $535 \mathrm{~nm}$. The concentration of IAA was determined from the standard curve of IAA.

\section{Ammonium production assay on stress condition}

Nitrogen fixation detected by ammonium production assay. Actinobacteria culture was inoculated into nitrogen-free broth medium amended with $3 \% \mathrm{NaCl}, 600 \mathrm{mg} / \mathrm{L} \mathrm{Fe}, 750 \mathrm{mg} / \mathrm{L} \mathrm{Al}$, and $\mathrm{pH} 3$, subsequently incubated for 14 days in a rotary shaker at 200 rpm. Each test was made at triplicate. A total of $1 \mathrm{~mL}$ Nessler reagent was added to $1 \mathrm{~mL}$ of supernatant and the mixture was added with ammonia-free distilled water up to $10 \mathrm{~mL}$. The optical density was measured using spectrophotometer at $450 \mathrm{~nm}$. The concentration of ammonium was determined from a standard curve of ammonium sulfate ranging from 0.1 to $1 \mathrm{mmol} / \mathrm{mL}$.

\section{Inoculum test on stress condition assay}

Five potential actinobacteria isolates were grown in $50 \mathrm{~mL}$ ISP 2 medium amended with $3 \% \mathrm{NaCl}, 600 \mathrm{mg} / \mathrm{L} \mathrm{Fe}, 750 \mathrm{mg} / \mathrm{L}$ $\mathrm{Al}$, and $\mathrm{pH} 3$, then incubated for 10 days on a rotary shaker at 200 rpm. Each test was performed at five replications. Following incubation period, actinobacteria mycelium was filtered using Whatman paper No. 1, to obtain for measurement of mycelium dry weight. This inoculum was also measured for its ability to produce IAA, siderophore, and ammonium under normal and stress conditions as previously mentioned.

\section{Analysis of metals residuals}

Ferric and aluminum residuals of the supernatants were determined by atomic absorption spectrophotometry.

\section{Evaluation of seedling growth-promoting actinobacteria}

The growth-promoting activity was evaluated by the Ragdoll method as described by Sreevidya et al. ${ }^{4}$ In brief, paddy seeds were surface sterilized by using 3\% sodium hypochlorite solution for 1 minute, alcohol $96 \%$ for 1 minute, alcohol $75 \%$ for 1 minute, and washed thoroughly with sterilized distilled water. Sterilized seeds were soaked in actinobacteria inoculum which incubated on stress condition (ISP2 broth medium containing $200 \mathrm{mg} / \mathrm{L}$ L-tryptophan with amended $3 \% \mathrm{NaCl}, 600 \mathrm{mg} / \mathrm{L} \mathrm{Fe}, 750 \mathrm{mg} / \mathrm{L} \mathrm{Al}$, and $\mathrm{pH} 3$ ) for 2 hours and placed in one half of a wet paper towel. This tube was kept at room temperature for 7 days. At the end of incubation, $\%$ percentage of germination, root and shoot lengths were determined.

\section{Molecular identification of actinobacteria isolates}

The Genomic DNA was amplified by using the Polymerase Chain Reaction (PCR) with 16S-specific primers for actinobacteria, ${ }^{5,6}$ i.e. forward primer using primer $27 \mathrm{~F}\left(5^{\text {ee }}\right.$ AGAGTTTGATCCTGGCTCAG-3 $\left.{ }^{* e}\right)$ dan 16Sact1114R (5"GAGTTGACCCCGGCRGT- $\left.3^{\circ}\right)$. The PCR reaction was carried out at the following mixture: $0.5 \mathrm{~mL}$ of DNA polymerase enzyme LaTaq (long amplification Taq polymerase), $25 \mathrm{~mL}$ of $2 \times \mathrm{GC}$ buffer, $8 \mathrm{~mL}$ of dNTP mixture, $1.5 \mathrm{~mL}$ of each primer (10 pmol), $9.5 \mathrm{~mL}$ of $\mathrm{ddH}_{2} \mathrm{O}$, and $4 \mathrm{~mL}$ of DNA template. The PCR condition was as follows: pre-denaturation $\left(94^{\circ} \mathrm{C}, 4\right.$ minutes $)$, denaturation $\left(94^{\circ} \mathrm{C}, 45\right.$ seconds $)$, annealing $\left(55^{\circ} \mathrm{C}, 1 \mathrm{~min}\right)$, elongation $\left(72^{\circ} \mathrm{C}, 1 \mathrm{~min} 10 \mathrm{sec}\right)$, and post-PCR $\left(72^{\circ} \mathrm{C}, 7\right.$ minutes $)$ for 30 cycles. The raw sequencing data were trimmed and assembled using ChromasPro program version 1.5. The actinobacteria were identified by entering the primary data on the EzBioCloud web. Furthermore, data were aligned using MEGA 7.0, while the phylogenetic tree was constructed using the Neighbor-Joining method with bootstrap $1000 \times$ replications. $^{5}$ 


\section{Results and Discussion}

\section{Growth of actinobacteria isolate under environmental stress}

Physiological characteristics of 10 isolates producing the highest siderophore were studied, with regard to their growth under environmental stress ( $\mathrm{pH}, \mathrm{NaCl}$, heavy metals) in tidal swamps. The result showed that, all of the sponge-associated actinobacteria had a noticeable difference in their growth. Some isolates were incapable of growing in ISP2 medium at $\mathrm{pH} 4$; in contrast, all the isolates could well grow at the higher levels of $\mathrm{pH} 5,6$, and 7. The most tolerant isolate at the condition of $\mathrm{pH} 4$, as commonly found in a tidal swamp, was attributed to Cal24h, yielding $193 \mathrm{mg}$ of mycelium dry weight. Tamreihao et al. ${ }^{7}$ reported that Streptomyces sp. MBRL 10 was known as an acidophilic isolate, and capable of producing IAA, siderophore, and antifungal compounds, which make it possible to serve as growth promoting for rice plant.

The present work also showed that all sponge-associated actinobacteria isolates exhibited a favorable tolerance against salinity (up the concentration of 7\%). In this case, the most tolerant isolate was found at Cal24h, reaching up to $251 \mathrm{mg}, 533 \mathrm{mg}, 539 \mathrm{mg}$, and $576 \mathrm{mg}$ for each level of $\mathrm{NaCl}$ (1, 3, 5, 7\% respectively). Previously, Qin et al. ${ }^{8}$ reported that isolate of endophytic actinobacteria (KLBMP 5084) was capable of growing in ISP2 medium with $\mathrm{NaCl}$ concentration of $7 \%$. Gong et al. ${ }^{9}$ also isolated 91 actinobacteria isolates in a starch-arginine agar medium with addition of $3 \% \mathrm{NaCl}$, finding two potential isolates, i.e. S0051 and S0019 with a high salinity-tolerant up to 5\% and $11 \%$.

$\mathrm{Fe}$ and $\mathrm{Al}$ are frequently found as heavy metals in the tidal area. The sponge-associated actinobacteria could show high tolerance against Fe $800 \mathrm{mg} / \mathrm{L}$ and Al $1000 \mathrm{mg} / \mathrm{L}$. In our experiment, the highest tolerable level of $\mathrm{Fe}$ and $\mathrm{Al}$ was found at 600 $\mathrm{mg} / \mathrm{L}$ and Al $1000 \mathrm{mg} / \mathrm{L}$, achieved by isolate Car21t of $219 \mathrm{mg}$ and $217 \mathrm{mg}$ respectively. Latha et al. ${ }^{10}$ successfully performed isolation of Streptomyces (isolated from chicken feces) resistant to heavy metals $(\mathrm{Cr}, \mathrm{Ni}, \mathrm{Zn}$, and $\mathrm{Pb}$ ). The resistance of the isolate may result from adaptation following continuous exposure to heavy metals via contaminated water and feed. Actinobacteria isolate was found dominant at rhizosphere and resistant to $\mathrm{Ni}$ and Co. ${ }^{11}$ In addition, Charter ${ }^{12}$ asserted that actinobacteria also produced spores; thus, they possessed a tremendous survival ability in various environmental stresses. Based on physiological characterization, five isolates that demonstrating the best growth were determined, i.e. Car21t, Cal31t, Crc32t, Dbi28t, and Cal24h. They appeared to differ in growth performance under stressed conditions in ISP2 medium $(\mathrm{pH} 4)$ with an addition of $3 \% \mathrm{NaCl}, 600 \mathrm{mg} / \mathrm{L} \mathrm{Fe}$, and $750 \mathrm{mg} / \mathrm{L} \mathrm{Al}$. Alvarez et al. ${ }^{11}$ showed that siderophore-producing actinobacteria might also chelate a variety of heavy metals including $\mathrm{Fe}, \mathrm{Al}, \mathrm{Cu}, \mathrm{Cd}, \mathrm{Ni}$, and $\mathrm{Pb}$. At the presence of these heavy metals in the environment, the formation of siderophore-heavy metal complex occurred. ${ }^{13}$ This indicates that siderophore serves as a key component generated by actinobacteria for reducing and adapting to heavy metals, including $\mathrm{Fe}$ and $\mathrm{Al}$ as observed in a tidal swamp.

\section{Plant growth promoting activities of potential actinobacteria}

The results showed that five potential isolates, having good adaptability under various environmental stresses, differently demonstrated production of ammonia, IAA hormone, and siderophore with presence of the stressors. The experimental data exhibited that sponge-associated actinobacteria could generate siderophore, although their growth environment was at stress condition (Figure 1). Interestingly, it found that siderophore was more produced with presence of the stressors in a tidal swamp. Ji et al. ${ }^{14}$ investigated the role of siderophore desferrioxamine B in enhancing absorption of $\mathrm{Fe}$ and $\mathrm{Pu}$, suggesting that the siderophore synthesized by actinobacteria possessed an affinity to both $\mathrm{Fe}$ and $\mathrm{Pu}$. In addition, Rungin et al. ${ }^{15}$ reported that siderophore from actinobacteria enabled to raise plant growth up to $100 \%$, in comparison with the growth of plant inoculated with siderophore mutant strain.

IAA hormone produced by the plant with the stress imposed by the environment was at a range of $1-3 \mathrm{mg} / \mathrm{L}$. Similarly, Dimkpa et al. ${ }^{16}$ found that the existence of environmental stress could exhibit a remarkable effect on the production of IAA hormone. Isolate Streptomyces spp. could produce IAA hormone of $5 \mathrm{mg} / \mathrm{L}$ under normal condition, but under stress condition it was significantly decreased up to $2 \mathrm{mg} / \mathrm{L}$. In contrast, more ammonium was produced by the five isolates with the presence of stressors, compared to that produced under normal condition. Investigation on the nitrogen-fixing ability of actinobacteria under conditions of salt stress has been reported by Qin et al. ${ }^{8}$ Isolate Streptomyces sp. KLBMP5084 was known capable of growing in N-free medium, while, in the $250 \mathrm{mM} \mathrm{NaCl}$ treatment, root length of the inoculated plant was noticeably increased by $27.3 \%$.

Regarding performance of the five potential actinobacteria isolates, the experimental data suggested that synthesis of plant growth-promoting compounds still occurred. During exposure to stress conditions, production of IAA, ammonium, siderophore was found to be higher compared to those produced during the normal condition (Figure 2). The actinobacteria inoculum produced IAA of $1.64 \mathrm{mg} / \mathrm{L}$ under normal condition, while more IAA was synthesized under environmental stress, i.e. $3.21 \mathrm{mg} / \mathrm{L}$. Actinobacteria inoculum could facilitate nitrogen fixation; consequently, higher nitrogen level $(2.46 \mathrm{mg} / \mathrm{L})$ was produced in stress condition compared to that produced in normal condition $(1.97 \mathrm{mg} / \mathrm{L})$. Additionally, this was augmented by the amount of siderophore unit generated, reaching up to $1.44 \%$ in normal condition and $1.64 \%$ in stress condition. This present work also showed that actinobacteria inoculum enabled to dissolve phosphate up to 0.64 $\mathrm{mg} / \mathrm{L}$ under stress condition.

In terms of heavy metal reduction, actinobacteria inoculum enabled to attenuate concentration of $\mathrm{Fe}$ and $\mathrm{Al}$, reaching up to $52 \%$ and $70 \%$, respectively. It proposed that siderophore served as heavy metal-reducing agent. Rajkumar et al. ${ }^{17}$ stated that the production of siderophore by bacteria might be altered by some factors, including the presence of heavy metal in which they exist. Siderophore showed the ability to dissolve and reduce the level of heavy metal; thus, it could be claimed to exert a beneficial role in soil normalization in ecosystem. ${ }^{18}$ The secondary metabolite was produced by microbe elicited by heavy metals. ${ }^{19}$

\section{Plant growth promoting of rice seedling by selected actinobacteria}

The effect of inoculum actinobacteria on rice seedling growth was demonstrated by ragdoll method in which all isolates exhibited an increase in root lengths, shoot lengths, and a number of root when compare with the control (Figure 3). The actinobacteria inoculum was proven effective to promote paddy seeds in both normal and stress condition. In normal condition, the inoculum could enhance the root lengths of $2.74 \%$ and shoot lengths of $0.29 \%$; however, a significant rise of the root and shoot lengths were observed under stress condition, i.e. $9.86 \%$ and $9.44 \%$, 
respectively. In addition, with the presence of environmental stresses exposed to rice plants, the actinobacteria inoculum increased a number of the plant's roots up to $13.93 \%$. Retnowati et $a l .{ }^{20}$ showed that five actinobacteria isolates could produce plant growth-promoting properties, such as N-fixing activities, phosphate solubilization, production of IAA, Hydrogen Cyanide, antibacterial and antifungal agents.

\section{$\mathbf{A}$}

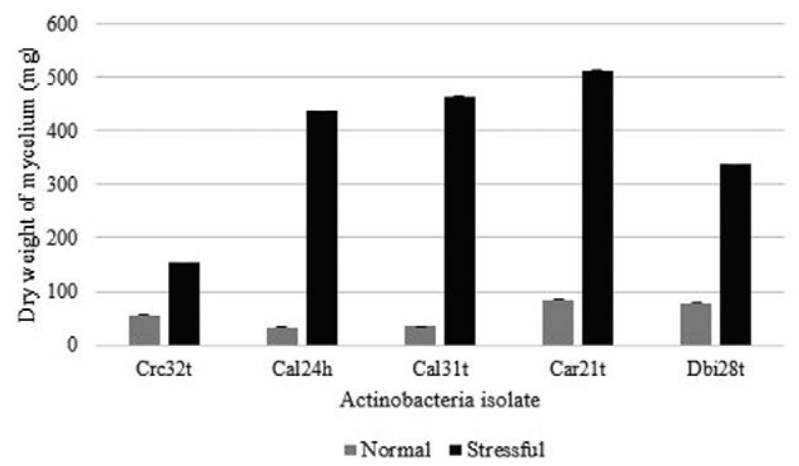

C

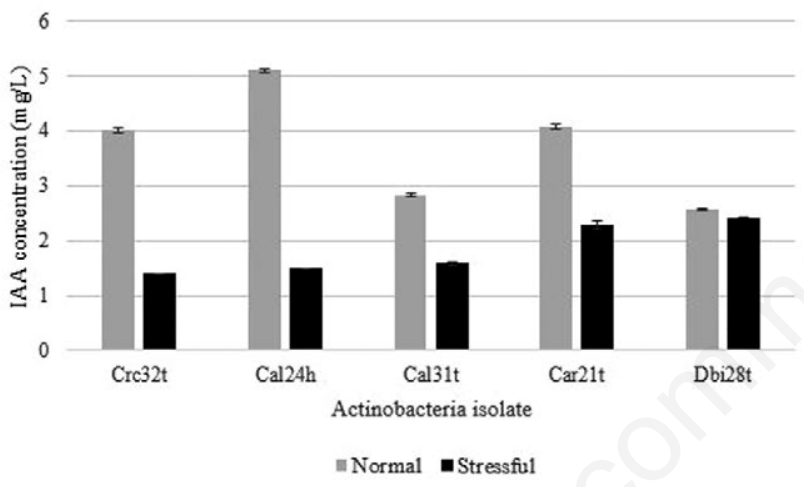

The molecular identity of potential sponge-associated actinobacteria

Based on partial sequences (1087 bp) of 16S rRNA using primer 27F and Sact1114R, the results of the homology search by EzTaxon program are shown in Table 1. In the phylogenetic analysis, the actinobacteria diversity within genera varied. According to the similarity of $16 \mathrm{~S}$ rRNA gene analysis, 5 strains belonged to

\section{B}

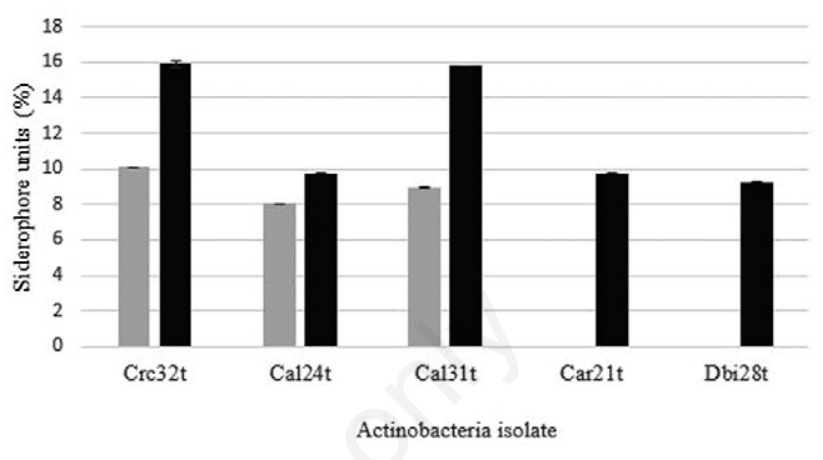

D

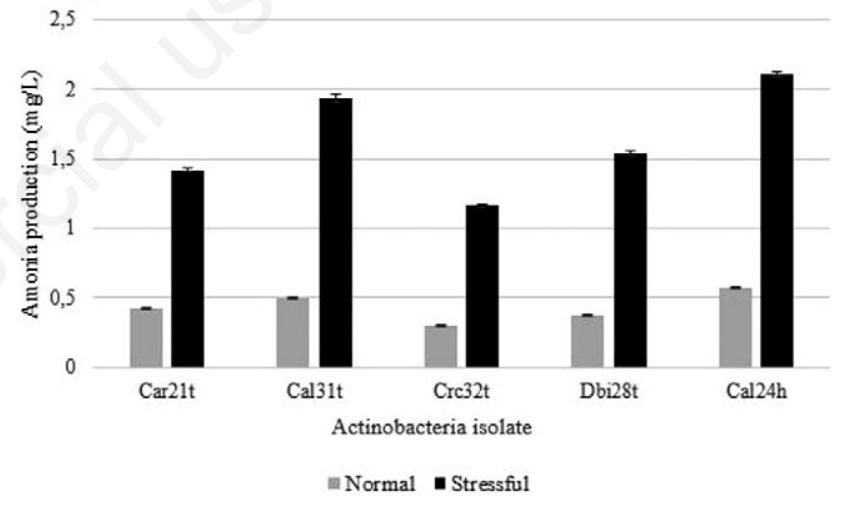

Figure 1. The ability of potential sponge-associated actinobacteria to produce various plant growth promoting bioactive compounds. A) Dry weight mycelium; B) siderophore units production; C) Indole Acetic Acid concentration; D) Amonium production.

Table 1. Percent similarity of $16 S$ rRNA gene sequence.

\begin{tabular}{|c|c|c|c|c|c|}
\hline Isolates & Species affiliation & Accession number & Similarity (\%) & Completeness (\%) & $\begin{array}{l}\text { Different/Total } \\
\text { sequenced }\end{array}$ \\
\hline Car21t & $\begin{array}{l}\text { Streptomyces tendae ATCC } 19812 \\
\text { Streptomyces violacerubidus LMG } 20319 \\
\text { Streptomyces trotolerans DAS } 165\end{array}$ & $\begin{array}{c}\text { D63873 } \\
\text { AJ81374 } \\
\text { DQ345779 }\end{array}$ & $\begin{array}{l}87.34 \\
87.33 \\
87.15\end{array}$ & $\begin{array}{l}100 \\
100 \\
100\end{array}$ & $\begin{array}{l}137 / 1082 \\
137 / 1081 \\
139 / 1082\end{array}$ \\
\hline Cal24h & $\begin{array}{l}\text { Streptomyces tendae ATCC } 19812 \\
\text { Streptomyces tritolerans DAS } 165 \\
\text { Streptomyces rubrogriseus LMG } 20318\end{array}$ & $\begin{array}{l}\text { D63873 } \\
\text { DQ345779 } \\
\text { AJ781373 }\end{array}$ & $\begin{array}{l}99.81 \\
99.72 \\
99.72\end{array}$ & $\begin{array}{l}100 \\
100 \\
100\end{array}$ & $\begin{array}{l}2 / 1069 \\
3 / 1069 \\
3 / 1068\end{array}$ \\
\hline Cal31t & $\begin{array}{l}\text { Streptomyces tendae ATCC } 19812 \\
\text { Streptomyces tritolerans DAS } 165 \\
\text { Streptomyces violaceorubidus LMG } 20319\end{array}$ & $\begin{array}{c}\text { D63873 } \\
\text { DQ345779 } \\
\text { AJ781373 }\end{array}$ & $\begin{array}{l}99.72 \\
99.62 \\
99.62\end{array}$ & $\begin{array}{l}100 \\
100 \\
100\end{array}$ & $\begin{array}{l}3 / 1063 \\
4 / 1063 \\
4 / 1062\end{array}$ \\
\hline Dbi28t & $\begin{array}{l}\text { Streptomyces tendae ATCC } 19812 \\
\text { Streptomyces rubrogriseus LMG } 20318 \\
\text { Streptomyces marokkonensis Ap1 }\end{array}$ & $\begin{array}{l}\mathrm{D} 63873 \\
\mathrm{AJ} 81373 \\
\mathrm{AJ} 965470\end{array}$ & $\begin{array}{l}87.21 \\
87.10 \\
87.02\end{array}$ & $\begin{array}{l}100 \\
100 \\
100\end{array}$ & $\begin{array}{l}137 / 1071 \\
138 / 1070 \\
139 / 1071\end{array}$ \\
\hline Crc32t & $\begin{array}{l}\text { Streptomyces rubrogriseus LMG } 20318 \\
\text { Streptomyces marokkonensis Ap1 } \\
\text { Streptomyces lienomycini LMG } 20091\end{array}$ & $\begin{array}{l}\text { AJ781373 } \\
\text { Aj965470 } \\
\text { AJ } 81353\end{array}$ & $\begin{array}{l}87.69 \\
87.61 \\
87.52\end{array}$ & $\begin{array}{l}100 \\
100 \\
99.2\end{array}$ & $\begin{array}{l}136 / 1105 \\
137 / 1106 \\
138 / 1106\end{array}$ \\
\hline
\end{tabular}


genus Streptomyces. Two isolates i.e. Cal31t and Cal24h were submitted to GenBank with accession number MK499453 and MK499454, respectively. The phylogenetic tree of 16S rRNA sequences was constructed and shown in Figure 4. The phylogenetic tree depicted three isolates, i.e. Crc32t, Dbi28t, and Car21t, grouped in the particular cluster which might be a novel species from genus Streptomyces. This is also in agreement with results from EzTaxon, demonstrating a low the similarity of $<97 \%$ (Table 1). As mentioned by Meier-Kolthoff et al., ${ }^{21}$ similarity of $<97.6 \%$ in 16S rRNA gene best described that the maximum probability of the strain representing similar species was only $0.01 \%$. This is noteworthy that further analysis including physiology and biochemistry are necessary to ensure the novelty of the three promoted isolates. Sponges contained diverse actinobacterial groups, however, the ecological functions of the actinobacteria are hardly known. Sponge-associated actinobacteria produce bioactive small molecules as their terrestrial counterparts do. The possibility cannot be excluded that some compounds play an important role in the chemical ecology of sponge hosts. ${ }^{22}$

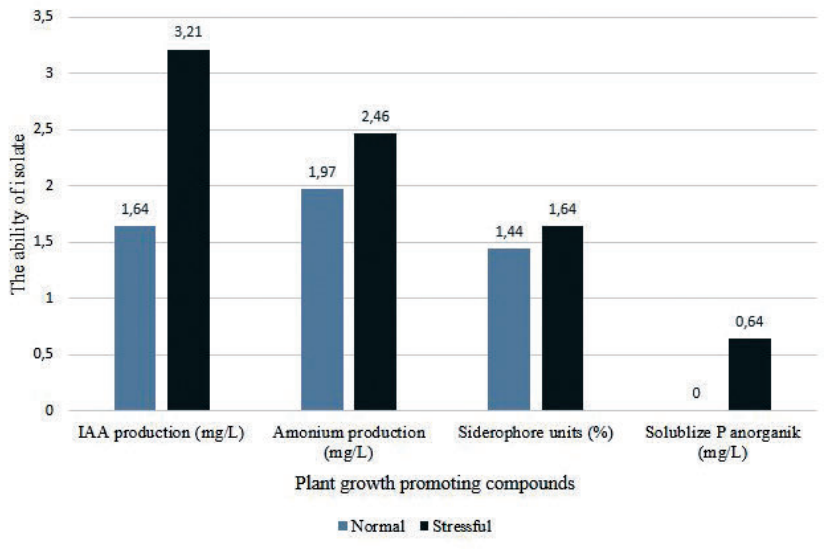

Figure 2. Various plant growth promoting compounds produced by inoculum sponge-associated actinobacteria.
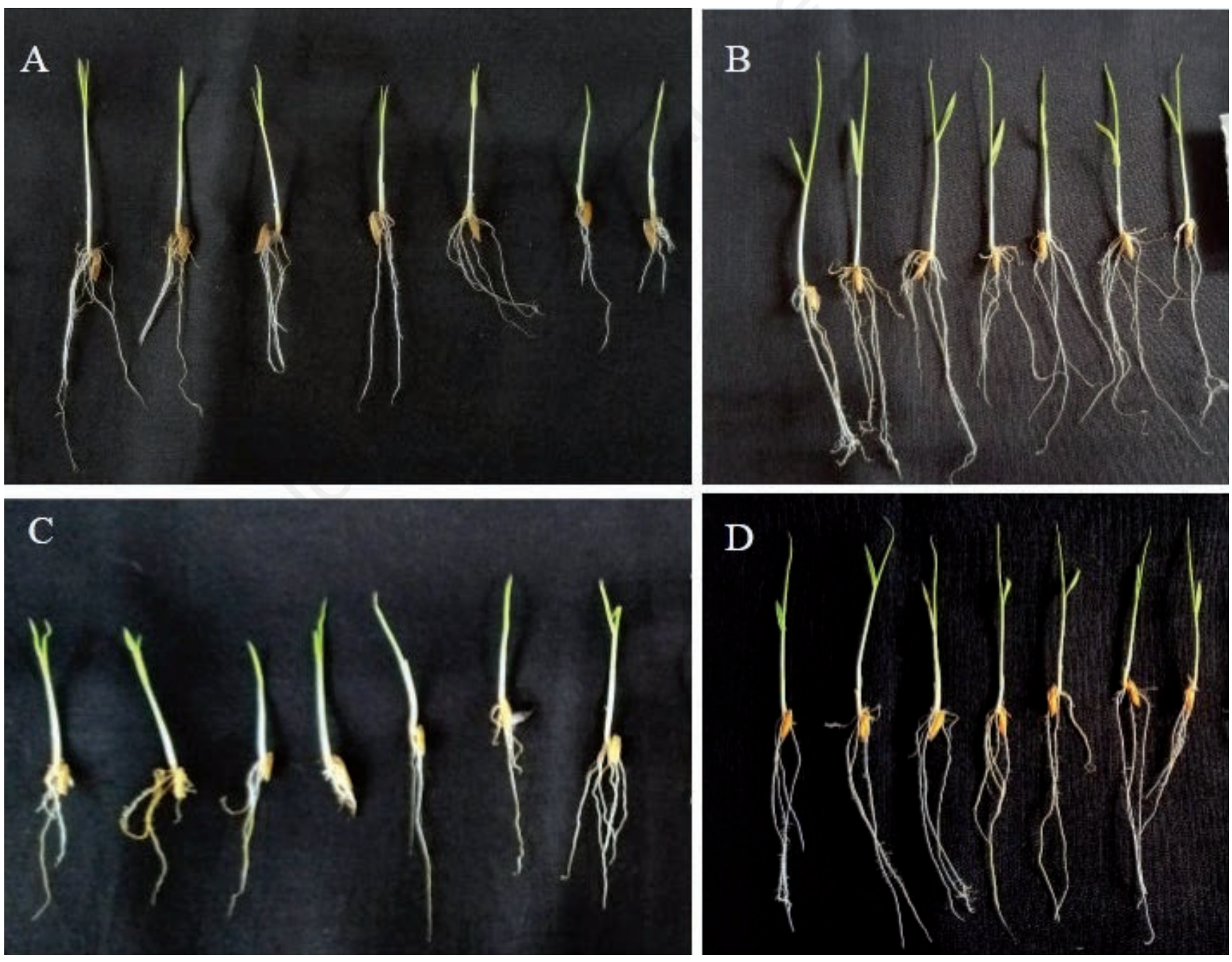

Figure 3. Effect of inoculation of potential sponge-associated actinobacteria on root and shoot lengths of rice seedlings. A) Control in normal medium; B) inoculum in normal medium; C) control in stressful medium; D) inoculum in stressful medium. 


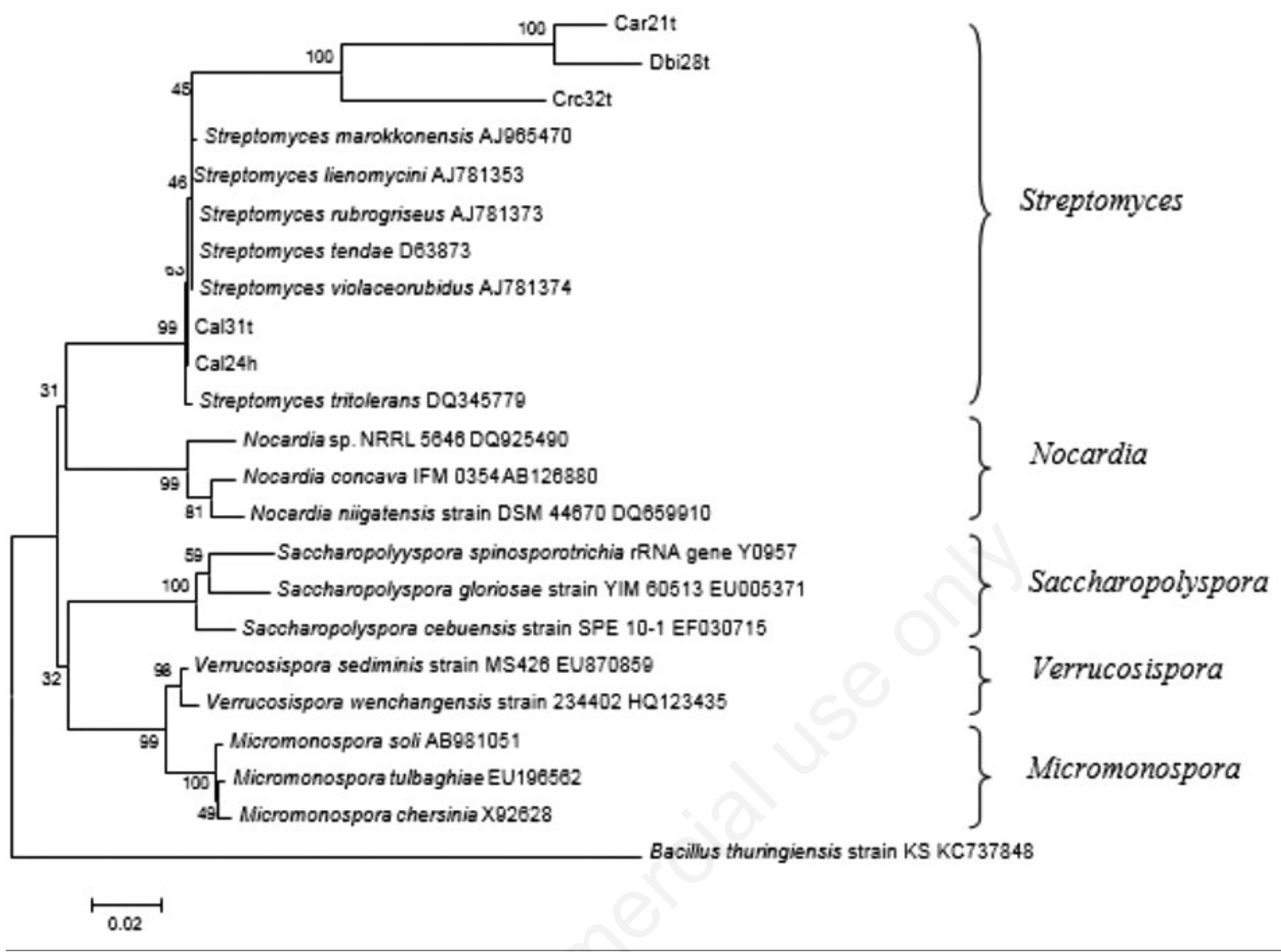

Figure 4. Phylogenetic tree of potential sponge-associated actinobacteria based on $16 \mathrm{~S}$ rRNA gene which is closely related to the bacteria inside or outside the group. This phylogenetic tree was constructed using Neighbor Joining method with bootstrap $1000 \times$ replications.

\section{Conclusions}

This research has succeeded in exploring the potency of sponge-associated actinobacteria to survive and produce plant growth promoting bioactive compounds based on environmental stresses which mimic tidal swamp characters. Five potential actinobacteria isolates, i.e. Car21t, Cal31t, Crc32t, Dbi28t, Cal24h displayed ability in the production of IAA, siderophore, and nitrogen fixation in ISP2 medium at $\mathrm{pH} 4$ and treated with $3 \% \mathrm{NaCl}, 600$ $\mathrm{mg} / \mathrm{L} \mathrm{Fe}$, and $750 \mathrm{mg} / \mathrm{L} \mathrm{Al}$. In addition, the five potential isolates considerably enhanced root length, shoot length, and root number. Based on molecular identification, all five potential isolates belonged to genus Streptomyces. The results suggested that sponge-associated actinobacteria could be used as plant growth promoter based on their tidal swamp characters.

\section{References}

1. Wang W, Qiu Z, Tan H, Cao L. Sideropore production by actinobacteria. Biometals 2014;27:623-31.
2. Schwyn B, Neilands JB. Universal chemical assays for the detection and determination of siderophore. Anal Biochem 1987; 160: 47-56.

3. Patten CL, Glick BR. Role of Pseidomonas putida indoleacetic acid in development of the host plant root system. Appl Environ Microbiol 2002;68:3795-801.

4. Sreevidya M, Gopalakrishnan S, Kudapa H, et al. Exploring plant growth-promotion actinomycetes from vermicompost and rhizosphere soil for yield enhancement in chickpea. Braz J Mircrobiol 2016;47:85-95.

5. Felsenstein J. Confidence limits on phylogenies: an approach using the bootsrap. Evolution 1985;39:783-91.

6. Marchesi JR, Sato T, Weightman AJ, et al. Design and evaluation of useful bacterium-specific PCR primers that amplify genes coding for bacterial 16S rRNA. Appl Environ Microbiol 1998;64:795-9.

7. Tamreihao K, Ningtoujam DS, Nimaichand S, et al. Biocontrol and plant growth promoting activities of a Streptomyces corchorusii strain UCR3-16 and preparation of powder formulation for application as biofertilizer agents for rice plant. Microbiol Res 2016;192:260-70.

8. Qin S, Feng WW, Wang TT, et al. Plant growth-promoting effect and genomic analysis of the beneficial endophyte 
Streptomyces sp. KLBMP 5084 isolated from halophyte Limonium sinense. Plant Soil 2017;416:117-32.

9. Gong Y, Bai JL, Yang HT, et al. Phylogenetic diversity and investigation of plant growth-promoting traits of actinobacteria in coastal salt marsh plant rhizospheres from Jiangsu, China. Syst Appl Microbiol 2018;41:516-27.

10. Latha S, Vinothini G, Dhanasekaran D. Chromium [Cr(VI)] biosorption property of the newly isolated actinobacterial probiont Streptomyces warreansis LD22. 3 Biotech 2015;5:423-32.

11. Alvarez A, Saez JM, Costa JSD, et al. Actinobacteria: Current research and perspectives for bioremediation of pesticides and heavy metals. Chromosphere 2017;166:41-62.

12. Charter KF. Genetics of differentiation in Streptomyces. Annu Rev Microbiol 1993;47:685-713.

13. Bankar A, Nagaraja G. Recent trends in biosportion of heavy metals by actinobacteria. In: Singh BP, Gupta VK, Passari AK, eds. New and future developments in microbial biotechnology and bioengineering. Chennai, India: Elsevier; 2018. pp 257-275.

14. Ji C, Juarez-Hernandez RE, Miller MJ. Exploiting bacterial iron acquisition: siderophore conjugates. Future Med Chem 2012;4:297-313.

15. Rungin $S$, Indananda $C$, Suttiviriya $P$, et al. Plant growth enhancing effects by a siderophore-producing endophytic streptomycete isolated from a Thai jasmine rice plant (Oryza sativa cv.
KDML105). A Van Leeuw J Microb 2012;102:463-472.

16. Dimkpa CO, Svatos A, Dabrowska P, et al. Involvement of siderophores in the reduction of metal-induced inhibition of auxin synthesis in Streptomyces sp. Chromosphere 2008;74:19-25.

17. Rajkumar M, Ae N, Prasad M, Freitas H. Potential of siderophore-producing bacteria for improving heavy metal phytoextraction. Trends Biotechnol 2010;23:142-9.

18. Ansari RA, Mahmood I, Rizvi R, et al. Siderophores: augmentation of soil health and crop productivity. In: Kumar V, Kumar M, Sharma S, Prasad R, eds. Probiotics agroecosystem. Singapore: Springer; 2017. pp 291-312.

19. Shams Ul Hassan S, Jin HZ, Abu-Izneid T, et al. Stress-driven discovery in the natural products: A gateway towards new drugs. Biomed Pharmacother 2019;109:459-67.

20. Retnowati D, Solihin DD, Ghulamahdi M, et al. New information on the potency of sponge-associated actinobacteria as producer of plant growth-promoting bioactive compounds. Malays Appl Biol 2018;47:127-35.

21. Meier-Kolthoff JP, Göker M, Spröer C, Klenk HP. When should a DDH experiment be mandatory in microbial taxonmy? Arch Microbiol 2013;195:413-8.

22. Sun W, Zhang F, He L, et al. Actinomycetes from the South China Sea sponges: isolation, diversity, and potential for aromatic polyketides discovery. Front Microbiol 2015;6:1-15. 